\title{
SOBREVIIIR A LA PANDEMIA: MANUAL DE RESISTENCIA Y ADAPTACIÓN DE UNA PEQUEÑA ESCUELA PRIVADA DE DANZA'
}

\author{
SURVIVING THE PANDEMIC: RESISTANCE AND ADAPTATION MANUAL OF A SMALL PRIVATE SCHOOL OF DANCE
}

\author{
Paco Montemayor \\ Escuela de Danza Maica, Córdoba (España) \\ pacomontemayor2@gmail.com \\ (c) (i) $(9)$
}

\section{| Resumen |}

Durante el periodo comprendido entre marzo del pasado año y la actualidad, el mundo entero se ha visto obligado a modificar su conducta social debido a la irrupción de la pandemia de la COVID-19. Las limitaciones impuestas, como son la distancia de seguridad, el uso de mascarillas y la ventilación de los espacios cerrados, han perjudicado al funcionamiento ordinario de la escuela de danza desde dos perspectivas: la metodológica y la logistica. Los profesores y los alumnos han sido objeto de una adaptación impuesta por la realidad de la crisis sanitaria, que han ido asumiendo con una actitud positiva, anteponiendo su deseo de continuidad en el proceso enseñanza/aprendizaje, frente a las ostensibles y novedosas incomodidades sobrevenidas a la expansión del virus. En el presente articulo se pretende analizar la capacidad de resiliencia humana que está permitiendo desarrollar nuevos métodos y estrategias de transmisión y recepción de los conceptos técnicos y artísticos, compatibles con la algo ya manida nueva normalidad.

Palabras clave: Pandemia, Escuela de danza, Limitaciones, Resiliencia, Adaptación, Miedo, Actitud, Mascarillas.

\section{Abstract}

During the period between march of last year and today, the entire world has been forced to change its social behavior due to the outbreak of the COVID-19 pandemic. The limitations imposed, such as the safety distance, the use of masks, the ventilation of closed spaces, have affected the ordinary operation of the dance school from two perspectives: methodological, and logistics. Teachers and students have undergone an adaptation imposed by the reality of the health crisis, which they have been assuming with a positive attitude, putting their desire for continuity in the teaching/learning process before the ostensible and novel discomforts that have occurred the spread of the virus. This article aims to analyze the human resilience capacity that is allowing the development of new methods and strategies for the transmission and reception of technical and artistic concepts, compatible with the already hackneyed new normality.

Keywords: Pandemic, Dance school, Limitations, Resilience, Adaptation, Fear, Attitude, Masks.

${ }^{1}$ Recibido/Received: 01/|2/202|

Aceptado/Accepted: 21/0I/2022 


\section{| Introducción |}

La situación acaecida en el mundo a partir del primer trimestre del pasado año 2020 dejó un rastro de incertidumbre y, hasta cierto punto miedo, que aún hoy seguimos soportando, con marcada desigualdad en lo que a posibilidades de resiliencia se refiere, para los diferentes segmentos de población.

La COVID-19 golpeó con absoluta virulencia la línea de flotación de la economía mundial. En general, todos los sectores se vieron afectados, pero probablemente, la cultura ha sido uno de los más vulnerables, tanto durante el estricto confinamiento, como en la etapa posterior, en la que aún nos encontramos y para la que los brotes verdes empezaron a surgir hace unos meses.

No estábamos preparados para combatir adversidades de tal magnitud, pero ¿Acaso habría sido posible estarlo ante un asunto de semejante complejidad? Quizá nadie, en su sano juicio, hubiera pensado en tener que enfrentarse a esta experiencia nunca antes vivida, excepto en las distopías que algunos directores de cine reflejaron tiempo atrás en sus trabajos, y a las que hoy por hoy, pasada la parte más incierta de la pandemia, podríamos otorgar un notable grado de verosimilitud.

No es descartable hablar de dos retos principales en el abordaje de tan extraordinario panorama. El primero, coincidente en el tiempo con el segundo trimestre del 2020, focalizaría nuestros esfuerzos en las necesidades humanas más vitales: no contagiarse, mantener el mayor bienestar posible en el entorno doméstico, o curiosamente, aferrarse a la cultura como una tabla de salvación, productora de la salud emocional necesaria para paliar, al menos en parte, el desasosiego provocado por la pandemia y su ingente cantidad de daños colaterales. Una vez superada esta etapa, excepto para los sectores esenciales y aquellos susceptibles de poder afrontar el teletrabajo con cierta garantía de éxito, llegaría una segunda, en la que aún nos hallamos inmersos y cuya meta estaría en la recomposición del estatus anterior, en los casos que esto haya sido posible; o, en los peores escenarios, en la readaptación a nuevas formas laborales, hasta ese momento desconocidas para la gran mayoría de quienes lo han intentado y continúan haciéndolo. Este último aspecto, será el núcleo central de la explicación sobre la experiencia vivida en una pequeña escuela privada de danza, expectante ante una "nueva normalidad" $y$ abocada al descubrimiento de herramientas metodológicas y comunicativas impensables desde su propia creación, allá por los años ochenta del siglo pasado.

\section{Preámbulo. Cuando la Covid-19 irrumpió en nuestras vidas de}

\section{la manera más abrupta |}

Recuerdo con absoluta claridad, creo que no lo olvidaré nunca, mi última clase presencial que impartí en Ciudad Real antes de la pandemia. Aquel jueves, 12 de marzo de 2020, la situación ya pintaba bastante mal, todos los indicios describían la confirmación de los nefastos augurios y así sucedió. Durante ese día las noticias empeoraban cada hora, los 
informativos y los rumores incrementaban el desconcierto y la tensión que se palpaba en el ambiente. En mi última hora de clase, bastante reducida ya en afluencia de alumnos, la directora de la escuela entró para informar de la suspensión, a partir del día siguiente, de la actividad docente en todos los niveles educativos en el plano autonómico. Era una evidencia que nuestro sector seguiría esa estela de actuación. El viaje de vuelta a Córdoba fue extraño, con un permanente ir y venir de preguntas que, obviamente, no tenían respuesta. El día siguiente nuestra comunidad autónoma tomó las mismas medidas restrictivas, extendidas ya al ámbito nacional, $y$, ante esta coyuntura, decidimos la suspensión de todas las clases hasta nuevo aviso. El 14 de marzo se publicó en el BOE el estado de alarma (R.D. 463/2020).

Al margen de lo familiar y personal, con la salud y los básicos cubiertos, el aspecto laboral acapara buena parte del pensamiento esos días. El modus vivendi está suspendido, sin fecha de retorno prevista. La primera decisión es conseguir, por todos los medios, que el contacto con el alumnado permanezca vivo, recurrí entonces a las redes sociales y establecí grupos de comunicación con ellos. Durante esos primeros días de encierro, compartimos inquietudes, miedos y dudas, aliviando mutuamente la angustia generada por lo incierto de nuestro futuro. Incluso empezamos a enviar pequeños videos con suaves ejercicios de movimiento de brazos, recordatorios de trabajo hecho en los últimos días de clase en la escuela, técnica de castañuelas o sesiones de trabajo de distintos ejercicios relacionados con la danza clásica para realizar en casa. Todo ello perseguía reforzar el vínculo profesor/alumno de manera más activa y siempre con la óptica puesta en la ansiada vuelta a clase. Desgraciadamente, la situación se fue alargando tras sucesivas prórrogas y, unos días después llegaron las clases online. Aunque había tenido alguna exitosa iniciativa previa a través de Skype, nunca hubiera imaginado llevar a término un programa de clases regulares de Danza Española desde casa, con zapatillas deportivas, creando un espacio válido entre el sofá y el mueble bar y, lo más rocambolesco de todo: a través de la pantalla del ordenador.

Fue, sin duda, una experiencia relativamente positiva, a pesar de los enormes condicionantes impuestos por el medio para desarrollar este tipo de actividad docente (Yébenes Cobos, 2021), donde lo más gratificante era observar la ilusión con que la mayoría de los asistentes esperaban el momento de la clase, describiéndolo a veces, como el mejor de cualquiera de aquellos duros e intensos días. Así transcurrieron aproximadamente tres meses, en los que cada tarde el salón de casa se convertía en aula improvisada, recibiendo virtualmente a todo el alumnado que quiso adaptar su modo de aprendizaje. Conseguimos dar forma a pequeñas coreografías que después, con la vuelta a la escuela, hemos recordado de forma muy emotiva y que, incluso en algún caso y con ligeros retoques, se ha llevado al escenario, constituyendo un emotivo tributo al difícil momento vivido.

El curso académico 2019/2020 quedó interrumpido, no pudiendo dar la conclusión habitual a éste, consistente en la representación en el teatro del trabajo desarrollado durante el periodo lectivo. Aun así, pudimos terminar las clases, aunque fuese de esta particular forma descrita antes. He de decir que todo este trabajo se hizo de manera 
completamente desinteresada por nuestra parte, movidos por el ánimo de compensar la confianza del alumnado en la escuela durante muchos años, y a pesar de su reacción contraria, que era la de insistir reiteradamente en el abono de sus clases. Actitud por la que estaremos siempre agradecidos, al igual que por sus regalos al terminar la actividad en ese extraño periodo académico.

\section{| Vuelta a la escuela con nuevos planteamientos |}

Llega el momento de afrontar el nuevo y, por completo desconocido, campo de actuación. Durante el verano se va gestando el "posible" plan de acción para ejecutar a partir de septiembre, pero la volubilidad resultante en cuanto a medidas restrictivas y de seguridad, no permite asentarlo con mucha solidez, así que nos moveremos al albur de aquello que se vaya decretando por parte de las autoridades competentes. El aluvión de cambios inicial es impactante. Septiembre nos trae la necesidad de aplicación inmediata de todo lo ideado previamente. En este sentido podríamos hablar de dos tipos de modificaciones: las que atañen directamente a los medios materiales, puestos al servicio de la prevención, esencialmente; y aquellas emocionales, que a mi juicio resultarían más difíciles de conjugar, dirigidas a contar con la confianza, empatía e ilusión de alumnos y alumnas que tenían ante sí la disyuntiva sobre su retorno a clase. Duda, incertidumbre y una marcada sensación de miedo al contagio, serían para ellos grandes enemigos a batir.

Materiales: un buen número de nuevos elementos empiezan a estar presentes, desde ese momento, en la actividad diaria de nuestra escuela de danza. Termómetros de medición rápida, dispensadores de gel hidroalcohólico, felpudos especiales de limpiado-secado a la entrada, cantidades ingentes de desinfectante viricida, medidores de $\mathrm{CO}_{2}$, leyendas indicativas sobre limitación de aforo en vestuarios, lavado de manos, obligatoriedad de uso de mascarilla, respeto estricto de la distancia social, etc. También solicitamos el menor uso posible de los espacios anexos a las aulas, como oficina, recibidor o vestuarios y aseos, llegando incluso a pedir a los padres del alumnado de menor edad (quizá la franja más afectada, en nuestro caso) la no entrada a las dependencias del centro, recogiendo nosotros mismos a los alumnos más pequeños en la puerta y devolviéndolos a sus padres al término de la actividad. Las tareas de limpieza, ventilación y desinfección se refuerzan ostensiblemente en base a conseguir la mayor asepsia posible en todos los espacios del recinto. Como medidas administrativas, instamos a que los abonos de las mensualidades se hicieran mediante transferencia, siempre que fuese posible, y a la comunicación telefónica o a través de la red, para solventar cualquier duda relacionada con la actividad habitual. Con todo ello conseguimos evitar el contacto directo en detrimento del añorado, y mucho más emotivo, cara a cara, que hoy vamos recuperando poco a poco, afortunadamente. Pasamos a utilizar, con mayor frecuencia que antes, mandos a distancia, micrófonos, o altavoces bluetooth, evitando así el tránsito por el espacio compartido en clase para actuar sobre el volumen o interrupción y activación de la música empleada. Por último, establecemos una delimitación de espacios en el interior de las aulas de unos dos metros por dos (incluso ligeramente superior al metro y medio 
que, en principio, marcaba la normativa). Optamos por dibujar en el suelo espacios cuadrados, con su centro definido, en los cuales, el alumno/a desarrollaría su trabajo de clase, teniendo una clara perspectiva respecto a sus límites de movimiento. Paralelamente, y pensando en obtener alguna rentabilidad pedagógica de esta medida, se me ocurre atribuir a cada uno de estos espacios el nombre y cronología básica de grandes personalidades de la danza, tanto española como clásica, a lo largo de la historia. Así, cuando comienzan o terminan su clase, explico brevemente, aunque con cierta grandilocuencia (más que nada, buscando incitar su curiosidad) el perfil del personaje cuyo nombre tienen presente, a sus pies, mientras están allí: "Hoy vais a bailar en casa de, o en homenaje a Antonio Ruiz Soler, Anna Pavlova, el Maestro José Granero, la Argentinita o Juanjo Linares, entre otros muchos”. Además, les invito a que profundicen en su conocimiento y, lo que es mejor, muchas veces son ellos los que preguntan antes, cuando leen la denominación del espacio que están ocupando ese día.

Emocionales: lo intangible, lo sensitivo, aquello que cada persona puede percibir o gestionar de forma completamente distinta, siempre resultará muy complejo de tratamiento, tanto desde el punto de vista de la propia aceptación, como desde el que afecta al modo de abordaje desde el exterior. ¿Cómo conseguir un cierto grado de comodidad en clase? ¿Está garantizada la seguridad frente a posibles contagios? ¿Puede adaptarse el binomio enseñanza-aprendizaje a un nuevo modelo, cargado de factores en contra y con unos resultados de testeo prácticamente inexistentes? Sólo el tiempo daría respuesta a estas preguntas. El comienzo de curso y las semanas sucesivas resultan determinantes para el desarrollo posterior. Todos vamos asumiendo paulatinamente el modus operandi inherente a la situación creada, mostrando la inmensa mayoría de los asistentes una notable implicación en cuanto a la disciplina necesaria para que todo pueda fluir, con relativa normalidad y en la medida de lo posible. La toma de temperatura diaria, el uso de desinfectante manual, la ubicación precisa en clase, la mascarilla siempre colocada, en muchos casos doble (en el mío, siempre), la no permanencia en las instalaciones, sino para la clase en sí, se convierten en actitudes cotidianas; pero el miedo y la desconfianza se encuentran presentes y esta sensación se aprecia. A pesar de ello, la cuestión más reiterada es redundante y surge tanto por parte del alumno, como del profesor: o esto o nada, no hay más opciones. Si observas, aprendes a leer las miradas y por encima del cubrebocas los ojos hablan, expresando lo sentido, a veces para bien y otras no tanto. En estos casos, la duda sobre lo acertado del camino elegido crece y se impone el replanteamiento, pero al final, vuelves sobre tus pasos. Quieres creer en lo correcto de esa forma de proceder y que el tiempo avale dicha actuación. Por suerte, el paso de los meses, aunque muy condicionado siempre por los empellones de las sucesivas olas, nos va aportando la dosis precisa de confianza para continuar avanzando. La administración de la vacuna también va contribuyendo a que las sensaciones mejoren y predispongan algo más la vuelta de alumnos que se mostraban reticentes al empezar el curso, incluso van apareciendo, poco a poco, potenciales clientes que demandan información sobre nuestra actividad, eso sí, con una batería de preguntas relativas a espacio o aforo que antes de la aparición del COVID-19 no solían estar entre las más consultadas. Al final, el manual de resiliencia va tomando forma y consolida el modelo, seguro que susceptible de mejora, pero válido hasta la consecución de la continuidad. A 
pesar de las enormes dificultades, del miedo y la reticencia, ha habido personas que han escenificado, nunca mejor dicho, la importancia de la danza en sus vidas, apostando por la asistencia a clase en momentos tan adversos (Ángel Echevarri, 2021). Me consta que, en ocasiones, soportando críticas o presiones en contra, de familiares o amigos que lo consideraban como algo perfectamente prescindible $o$, incluso, acusaciones de irresponsabilidad por correr riesgo innecesario de infección al permanecer en un lugar cerrado, practicando una actividad física exigente rodeada de otras personas ajenas a su propia "burbuja", para después volver a casa, quién sabe si con el virus. A fin de cuentas, no hablamos de una enseñanza obligatoria y la cultura, en general, no es vitalmente necesaria. Ellos han demostrado una valentía inusual y una profunda y verdadera pasión por la danza que espero les haya recompensado de forma proporcional. Nosotros, aunque apasionados también, defendemos un trabajo, del que vivimos y por el que luchamos para conseguir que sea valorado en su justa medida. Así que, al César lo que es del César, nuestros alumnos y alumnas son los realmente merecedores de tal reconocimiento.

\section{| Consecuencias |}

Desgraciadamente, es abrumadora la cantidad de circunstancias negativas derivadas de la crisis pandémica en el gremio de las escuelas de danza (Álvarez Cuadrado y Chávez Chávez, 2021). En el presente, muchos compañeros aún no han podido abrir sus puertas desde que se vieron obligados a cerrarlas hace ya año y medio. Es más, habrá muchos que no lo vuelvan a hacer, puesto que la necesidad les ha obligado a reciclarse en nuevos trabajos para poder afrontar una coyuntura económica familiar seriamente afectada por hipotecas, créditos varios, alquileres o mantenimiento de sus locales de negocio.

Tras el confinamiento inicial, nosotros, que fuimos afortunados, pudimos reabrir $y$ comenzar la actividad. Pero, a un escenario económico ya maltrecho, como consecuencia de la etapa previa de cierre, se suman los gastos extraordinarios destinados a medidas preventivas. Ese ahorro "preventivo", que los que trabajamos por cuenta propia destinamos a mantenimiento y mejora anual de las instalaciones, sirvió, en esta ocasión, para cubrir los gastos imprescindibles de suministros, comunidad y otros servicios básicos. Llega el momento ansiado y los alumnos vuelven a clase, pero en un número bastante reducido con respecto al curso anterior, sin embargo, los gastos siguen siendo los mismos, o incluso superiores en algunos casos. Con los factores en este orden, difícilmente va a cuadrar el producto. Las cuentas no salen y sólo conseguimos aguantar, aún con bastante dificultad, gracias a las pequeñas ayudas institucionales. Paradójicamente, mientras sufrimos esta notable disminución en los ingresos, nos vemos obligados a negar el acceso a nuevos alumnos que así lo solicitan por respetar la limitación de aforo, a pesar de contar con un espacio en aulas relativamente amplio en la comparativa con otros colegas. De las etapas de restricciones horarias en la actividad no esencial también pudimos salir bien parados, pues fuimos incluidos dentro de la considerada como educativa, con lo que no tuvimos que alterar los horarios ostensiblemente. A este respecto, tuvimos alguna visita de la policía local, recabando 
información que constatase que nos hallábamos dentro de la actividad permitida, aspecto que quedó resuelto satisfactoriamente. Aún así, sufrimos otro descalabro en forma de pérdida de alumnado que se sentía un poco temeroso a la hora de salir de la escuela y encontrar la calle prácticamente desierta en el momento de su vuelta a casa. No fueron muchos los que abandonaron, pero llovía sobre mojado. Con todos estos condicionantes, conseguimos llegar al final, con una situación económica al límite, pero exenta de deudas de consideración. En el horizonte queda la vuelta a una cierta normalidad, aunque asumo, día a día, que no se recuperarán valores equiparables a los de hace tan sólo un par de años, al menos a corto plazo. Desearía, y mucho, equivocarme en esta afirmación.

\section{| Adaptación a un nuevo modelo de enseñanza |}

Al margen de todas las medidas desgranadas ya en este texto, tanto de carácter higiénico-sanitario, como administrativas, que tienden a garantizar, hasta donde sea posible, la seguridad en el interior de la escuela; gestionar la docencia, desde su doble vertiente técnica y artística, ha supuesto, y continúa haciéndolo, recorrer un arduo camino plagado de escollos, en aras de la superación con resultados aceptables, de esta difícil etapa en la que todavía nos encontramos. Tratemos estos aspectos de manera diferenciada.

Desde el punto de vista técnico los condicionantes son numerosos. Además, la puesta en marcha se hace a sabiendas de la merma que producirán en la calidad de nuestra particular tipología de enseñanza. Un tema muy afectado ha sido el de la ocupación del espacio en clase y los supuestos prácticos que se van a exponer a continuación aportarán una clara visión. Piénsese en una sesión de centro de la especialidad de Danza Clásica donde el profesor proponía una diagonal de giros en pareja o en trío. Ahora, no sería viable. Lo correcto, o mejor menos incorrecto, radicaría en la ejecución individual, con lo que la clase sufre una ralentización demasiado acusada con la consiguiente pérdida de ritmo e intensidad. En la especialidad de danza española el desarrollo de una tabla de zapateado, a modo de escobilla, en la que deseamos incluir una figura de desplazamiento amplia en el contexto de nuestro trabajo percutivo no era precisamente producente y tampoco recomendable, dado que invadiría el espacio contiguo y la distancia social quedaría reducida. Si hablamos de la interactuación entre alumnos, debemos pensar en una afectación muy marcada. Coreográficamente, el trabajo del paso a dos, del trío, o de cualquier otro montaje grupal se ve seriamente modificado, debido a la separación establecida por el protocolo. Ni que decir tiene que el contacto físico queda muy limitado atendiendo a las circunstancias ya descritas. Las diferencias en los resultados serán más que evidentes en la comparativa con el trabajo que se realizaba dos años atrás, pero, aún así, esto no debe resultar invalidante. El esfuerzo se centrará en asumirlo, entendiendo que se optimizará la apariencia estética, en cuanto a la distribución espacial escénica, cuando la negativa situación sanitaria haya desaparecido o, al menos, mejorado ostensiblemente. 
En atención al plano artístico, entiendo que el mayor hándicap ha venido impuesto por el uso de la mascarilla. Es cierto que el bailarín/a se expresa de forma integral con su cuerpo, usado como vehículo de comunicación al servicio del arte; pero es baladí negar la importancia del rostro en esta función (Loreto, 2021). Llevando la mascarilla en clase, volcamos sobre los ojos toda la carga emotiva de nuestra interpretación, pero se añoran los matices que aporta el rictus. El dibujo de una sonrisa fresca o la mueca dolorosa en unos labios entreabiertos tienen que ser imaginados o intuidos ahora. Particularmente, intento suplir la carencia impuesta por la imposibilidad de imitación para el alumno, hablando sobre la emoción a describir, dibujando la figura metafórica adecuada para inducirlo a desarrollar su máxima vertiente expresiva. Incluso los comentarios jocosos al respecto pueden servir como herramienta válida para la consecución del objetivo, además aportan un grado de distensión que siempre se suele agradecer en clase.

Podría añadirse una tercera línea de perjuicio, ciertamente importante también, y, por tanto, otro frente abierto contra el que batallar: las limitaciones sobrevenidas que afectan al rendimiento físico y la confortabilidad en las aulas. En relación a esto, el último invierno fue duro; a pesar de no sufrir un clima extremo en Córdoba, las ventanas abiertas, para obtener la mayor ventilación posible, traían consigo una temperatura más baja de lo habitual, propiciando así unos comienzos de clase fríos, hasta conseguir un calentamiento adecuado. Tampoco fue raro, en absoluto, el uso continuado de sudaderas y otras prendas de abrigo durante el desarrollo de la actividad, complementos poco habituales y que no aportaban mucho al aspecto estético del estudiante o del profesor. ¿Se puede imaginar a alguien bailando por Soleá, ataviado con gorro de lana, coronado con un mullido pompón? Difícil de digerir, pero a pesar de la queja "térmica", también en este sentido podemos sentirnos afortunados, pues hemos tenido ventanas que poder abrir en la búsqueda de la tan traída ventilación cruzada, algo no siempre posible en el caso de muchos compañeros.

El hecho de tener que recortar los movimientos impuestos por el paso o la variación que se está marcando, también conlleva cierto desgaste físico en forma de cambios de dirección más cortos y de mayor impacto, gestos o desplantes más comedidos e impulsos que, una vez emitidos, deben atenuarse para mantener la distancia de seguridad requerida. Además, no es lo mismo realizar una mudanza en su extensión adecuada, que verte obligado a circunscribirla a dos metros cuadrados y prescindiendo de cualquier tipo de interactuación personal, menoscabando su apariencia estética. Pero sin duda, debemos volver a la mascarilla para significar la dificultad que ha supuesto, y lo sigue haciendo, su empleo mientras se despliega una actividad física intensa. La respiración se resiente ostensiblemente y el efecto ahogo se potencia. He podido ver mucha gente con mascarilla doble en clase y doy fe de la gran incomodidad que supone, pero aún así se ha sabido primar, por parte de todos los que decidimos afrontar el reto, lo realmente importante: vivir la enseñanza y aprendizaje de la danza del modo más llevadero durante este periodo, ojalá que transitorio y breve, que dejará paso a la restitución, como mínimo, de nuestro anterior modelo educativo. 


\section{| Conclusiones |}

El futuro se hace presente y ya, con el nuevo curso comenzado, podemos hacer balance de lo acontecido, resaltando, por encima de cualquier otra actitud, el comportamiento de todos los alumnos y alumnas que han apostado por la continuidad de la escuela con su asistencia incondicional, valiente y decidida. Esta reflexión, que está llegando a su fin, lo estaría haciendo de forma más penosa sin su inestimable colaboración.

Ahora, hasta podríamos sentirnos triunfadores en cierto modo, habiendo alcanzado el objetivo de seguir "vivos" y en condiciones válidas para dar forma a este nuevo periodo lectivo que empieza. Pero el futuro es incierto y no todo lo que se augura en positivo tendrá un aceptable grado de afianzamiento. Esta crisis, sin precedentes, llegó sin manual de instrucciones y la impresión, al menos la mía, es que vamos aprendiendo de ella a diario; conforme van surgiendo nuevos problemas, se generan soluciones con acierto desigual, como puede resultar obvio. Lo queramos asumir o no, la pandemia ha cambiado nuestro pensamiento, nuestros hábitos sociales y la percepción de vulnerabilidad ante nuevas enfermedades; incluso ha modificado nuestro orden de prelación en lo que respecta al desarrollo de actividades de ocio, culturales y educativas. En general, se atisba un incremento de la fobia a lugares cerrados, que normalmente presentarán mayor dificultad de ventilación. Quizá, nos volveremos más reticentes a permanecer demasiado cerca de otras personas, compartiendo espacios durante periodos de tiempo relativamente largos. Es posible, y espero fervientemente equivocarme, que la batería de dudas que ya surgía a la hora de elegir la danza como actividad a realizar, se vea incrementada, puesto que las nuevas prioridades establecidas parecen apuntar en otras direcciones. En nuestro caso, todos estos condicionantes se suman a los ya habituales durante la existencia de la escuela. Somos un pequeño centro privado, con más de treinta años de experiencia en Córdoba, que dependemos exclusivamente de nuestro volumen de alumnado, fluctuante cada año de manera irregular. Hemos vivido "modas" en lo que respecta a nuevas tendencias, periodos de prevalencia de "lo flamenco" sobre "lo estilizado" o "lo clásico" y viceversa, pero es cierto que este panorama no entraba en nuestros cálculos. Al final, como ya citaba en algún momento, somos seres resilientes y además, contamos con una ventaja añadida: nos mueve el corazón y el amor que sentimos por aquello que hacemos. Sólo espero poder comentar anecdóticamente, lo difícil que resultó trabajar en clase con la mascarilla puesta, dentro de diez o doce años.

\section{Referencias}

Álvarez Cuadrado, D. y Chávez Chávez, J. (2021). Afectaciones en academias de danza de Ecuador a causa de la pandemia por el COVID-19. Disponible en $<$ https://dspace.uartes.edu.ec/handle/123456789/489>.

Ángel Echeverri, L. (2021). La educación artística para el manejo de emociones en la pandemia del Covid-19. Disponible en <http://hdl.handle.net/10495/21035>. 
Loreto, S. (2021). La cara y la mascarilla: El rostro y su potencial expresivo en tiempo de pandemia. Disponible en < http://hdl.handle.net/10952/5004>.

Real Decreto 463/2020, de 14 de marzo, por el que se declara el estado de alarma para la gestión de la situación de crisis sanitaria ocasionada por el COVID-19.

Yébenes Cobos, M. (2021). La docencia virtual en tiempos de pandemia. Disponible en <https://hdl.handle.net/10953.1/14149>.

\section{Nota biográfica}

Paco Montemayor es un destacado bailarín y coreógrafo que aborda todas las disciplinas de la Danza Española, decantándose principalmente por el Flamenco y la Danza Estilizada, para las que ha creado un buen número de montajes corales e individuales. Desde hace más de treinta años ejerce docencia en la Escuela de Danza "Maica", de Córdoba, y en el Estudio de Danza "Esperanza de los Reyes, en Ciudad Real. 